\title{
Perceptions of Teachers Regarding the Inclusion of ICT in Teaching. The Case of Centro Universitario Ciénega
}

\author{
Ma. Del Carmen Nolasco Salcedo*, Liliana Serrano Zúñiga, Mireya Cacho Ruíz \\ Departmento de ciencias Básicas, Centro Universitario de la Ciénega, Universidad de Guadalajara, Ocotlán, Jalisco, México \\ *Corresponding author
}

\begin{abstract}
In this project, we sought to know and understand the perceptions of professors in computer education programs and computing concerning the use of Information and Communication Technologies (ICT) in order to propose communication-effective strategies that would promote the increased use of these tools through an interpretive study. For this, a mixed approach, based on surveys and semi-structured interviews with professors at Centro Universitario Ciénega, through which it was determined that some teachers continue to be reluctant to use ICT in their teaching practice. However, there is a large opening up toward the integration of ICT and agreement in stating that these tools comprise the teaching aids that the professor uses to manage the educational process in a different manner. Nonetheless, consideration of the use of technological tools in the classroom must derive from personal motivation and from recognition of the educational potential that they possess in the teaching-learning process, and not only for being on a par with the requirements of the current society. Strategies of awareness, motivation, and support by the Centro Universitario Ciénega and its academic departments are required for the effective integration of ICT in teaching.
\end{abstract}

Keywords: ICT, teachers, education, university center, Moodle

Cite This Article: Ma. Del Carmen Nolasco Salcedo, Liliana Serrano Zúñiga, and Mireya Cacho Ruíz, "Perceptions of Teachers Regarding the Inclusion of ICT in Teaching. The Case of Centro Universitario Ciénega." American Journal of Educational Research, vol. 5, no. 8 (2017): 908-912. doi: 10.12691/education-5-8-10.

\section{Introduction}

The University of Guadalajara in Mexico has proposed the incorporation of educative technologies and has generated in its interior the adequate decisions to modify their nature and tasks in processes of planning and academic organization and evaluation with the purpose of updating the challenges occasioned by the current knowledge society, where at present Information and Communication Technologies (ICT) follow the rhythm of the continuous scientific advances within a globalization framework.

In this context, the University of Guadalajara began a process of investment-modernization of the ICT in order to profile the University toward a new culture of quality and academic competitiveness. As part of that modernization, the University of Guadalajara created the Centro Universitario de los Valles (CUValles) and the Centro Universitario del Norte (CUNorte), which were established with an academic model that attempts to update the requirements of flexibility and support in ICT. The University of Guadalajara comprises six Metropolitan University Centers and nine Regional University Centers; similarly, the mission of each of these is to form high-quality professionals who maintain a high sense of social responsibility, who are creative, and who can solve the problems that they confront with a solid vision and equilibrium deriving from a respect for values and the maintenance of a commitment to the local and regional development of our society.
In the year 2000, University Centers CUValles and CUNorte initiated their academic activities with the necessary installations and the technological equipment outfits, in addition to an innovative academic-pedagogical model that implied different strategies, such as teachingpersonnel training in virtual ambiences, in order for these professors to have a pertinent academic profile, on-line instructional material, and presential and virtual counseling, among others. CUValles and CUNorte have grown and progressed with an accumulation of experiences and challenges, and have achieved comprising a dynamic component that furnishes critical awareness, autonomous knowledge, professional formation, technologies, and a culture society. In this regard, the Centro Universitario Ciénega is experiencing times of change that are driven by ICT, which have transformed social relationship and that, simultaneously, exert an influence on education-technologies relationships. For the professors, incorporating ICT into their daily tasks has become a challenge, due to that the teachers are not fully convinced of the role change and of allowing the students to be the protagonists of their own learning, with the professor becoming their adviserfacilitator. This implies that, because of the lack of security and of appropriate teacher-enabling programs, the creation of favorable conditions for their pedagogical use of ICT has not been achieved.

As noted by Olcott and Schmidt (2002, pp. 269 and 270) [5], the professorate is no longer the guardian of knowledge. The role that a teacher should play in a future should be akin that of an orchestra conductor: on the one 
hand, the latter should motivate, direct, and invest the musicians (the students) with autonomy, and in addition, should question, facilitate, and create a whole that is more than the sum of the individual parts (the students).

Hence, we find the importance of investigating the perception that teachers have concerning the use of ICT and of the institutional change that these generate, especially in educative programs in Informatics Engineering and Computer Engineering, which are directly related with ICT.

\section{Perception of Professors with Respect to ICT as Teaching-learning Tools}

According to the results of the surveys, the perception of the professors is fundamental for the effectiveness of the process of ICT use and appropriation, due to that formation of the future, obviously highlighting the educative level to which this refers, is characterized by a series of facts. From the latter, with the purpose of evaluating the methods carried out by Centro Universitario Ciénega in matters of teacher training, the following questions arise: Why do the professors of these programs not publish their curricular contents on an educative platform? What is the professors' perception regarding the use of ICT in the teaching-learning process?

In this context, the present work had as its objective to know the perceptions of the professors of informatics and computer educative programs the use of ICT in the educative process at Centro Universitario Ciénega, whose objective it is to make use of these ICT as didactic tools.

ICT are dynamic tools that offer synchronous and asynchronous communication. The incorporation of these technologies into the teaching body leads to a novel modality in the teaching-learning process; the Centro Universitario Ciénega affirms that the changes that have arisen from the use of the ICT are relevant, due to the autonomy of the drive of the students to be the leading actors of their own learning, to the advantage of aiding them in rediscovering their learnings.

Centro Universitario Ciénega has attempted to incorporate ICT into education in a gradual manner. Thus, it has offered training courses for its academic personnel, for the latter to come to know the benefits that these courses contribute to their teaching task, so that they can employ them later as support in the process. Notwithstanding this, even when the professors attempt to adapt themselves to the ICT, the idea is very well rooted in them that the best method is that of traditional teaching.

The teaching personnel of Centro Universitario Ciénega affirm that the student community prefers its classes to be held in the classroom, where the professor is the transmitter and the student, the receiver. It is necessary to train and inform the student community with respect to the advantages that ICT provide for their learning process, the skills that will be rediscovered in the students themselves. The students do not yet recognize that ICT do not only comprise a space to play, chat, and spend time.

The technological competence of the adviser-facilitator, as well as his/her beliefs and pedagogical practices, comprise important factors in the students' learning. The latter is achieved through tasks, exercises, and activities that should be interesting, didactic, and adequate (Nolasco, 2013) [4].

\subsection{Conception of the Professors of Technological Tools in Teaching}

It is generally considered that ICT are technological support tools to improve teaching-learning processes but, during the past years, greater weight has been given to these tools, leaving to one side the didactic or pedagogical importance that these can possess. The teaching personnel of Informatics Engineering and Computer Engineering educative programs affirm that they are aware that ICT are a necessary tool and that they make many contributions to the teaching-learning process in this educative model, and they explain that the incorporation of ICT per se does not guarantee that the education will be better. However, they consider that greater motivation is required on the part of the Institution to convince itself that these tools are truly the bearers of improvement in the quality of the education, that they are truly worthwhile and, rather than wholly abandoning the traditional teaching, they could combine both models, converting them into an optimal education model.

It is noteworthy that teachers have different alternatives for innovation in the classroom, thus co-constructing significant learning. In a glance at other tools, such as Facebook, Twitter, and YouTube, while these were not precisely created for educative activity, they have indeed provided spaces for sharing academic materials with students, due to that the latter spend a great deal of their time connected to these social networks. It is necessary to create spaces of dialog, of debate, to involve students in formative activity, with the knowledge of the benefits that are produced within the context, inserting these benefits into social networks for active learning, in which all of the members of the group collaborate in building knowledge and contributing to the learning of all.

It is worth mentioning that the majority of professors $(65 \%)$ who participated in this study prefer to utilize traditional teaching methodology, supporting themselves with ICT for the use of their classroom presentations.

On the other hand, teachers cite that it is the professor who, with his/her practice, determines the didactic-pedagogical quality during the teaching-learning process; nonetheless, the professorate is engaging in an effort to integrate ICT into its teaching, but the professors do not see their work rewarded in the attitude of the young people. This is due to that the students are more interested in direct contact with the professor, which implies the need to strengthen, in these young students, independent educative processes that aid in developing other potentialities.

It is evident that the lack of formation in ICT is the main reason that so many teaching personnel, as well as members of the student community, resist the role change that this new knowledge era implies. According to Roa and Stipcich [7], "The attitude of the professor, on occasion, is due to lack of information. Informatics is perceived as a threat, a challenge, just another innovation, 
leaving the professor with a skeptical attitude in the face of the potential improvements that ICT can contribute".

\subsection{ICT Utilized among University Professors}

The teaching personnel who participated in the case study affirm that the use given to ICT in their academic tasks is very basic, in that they utilize them for classroom activities.

According to the surveys, we observed that, of the tools that ICT provide for the generation of knowledge, those most utilized by the teaching personnel are the search engines, the presentation of information through videos, and oral presentations that make use of PowerPoint. In the meanwhile, as support for classroom activity, those employed for communication are electronic mail and the social networks, most specifically Facebook, to respond to doubts or to send works. Some professors made mention of utilizing podcasts and blogs, and the following figure shows the most utilized tools:

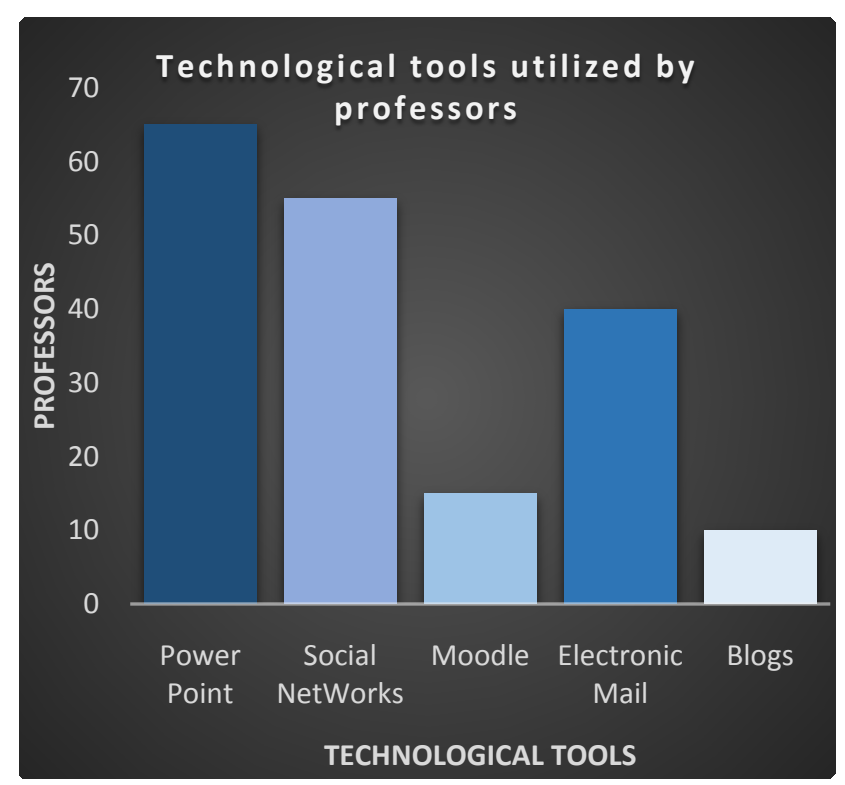

Figure 1. The most utilized tools by professors. Source: Own elaboration with the result of surveys conducted in professors

According to the previous graph, the tendency toward the use of ICT among university professors continues to be limited regarding the search and presentation of course content, due to the type of educative practices that predominating in these, in that, at present, the use of ICT has not promoted substantial changes in the educative courses-in-progress and that, in the majority of cases, utilize traditional tools. It is worthwhile mentioning that when ICT were introduced into the classroom, activities directed by the course professor diminished to the benefit of independent and cooperative activities; the didactic focus tends to be more constructivist and the students tend to integrate verbal and visual thought.

The increase of professor-student interaction, according to [1], "depends on two important matters: the teaching-learning activities that the professor generates and the attitude of the professor him/herself vis à vis the expression of the student".

"It is precisely through appropriation that the individual makes the technological tools his/her own, in order to utilize them in terms of their relationship with the sociocultural scenarios and activity contexts within which the individual is evolving" ([2]: p. 196).

It is necessary for the educative institution to carry out specific contributions in the formation of professors with respect to the use of ICT and their implementation in the classroom.

\section{Perception of University Policies for the Integration of ICT}

The role assigned by Centro Universitario Ciénega on this use of ICT as support tools in teaching-learning should be dynamic and motivational with respect to the academic activity, driving the use of technological tools in the educative task of the professorate, thus inserting the professor into this process of institutional transformation.

In terms of this topic, the professors consider that they can accept the role change that this modality implies. It is necessary for Centro Universitario Ciénega to maintain an elevated sense of academic responsibility, one involving a firm commitment to the professors, supplying them with different strategies as coadjuvants in order to potentiate the mechanisms currently employed through the ICT Integration Program directed toward the professorate.

Quintero-Calvache, Ávila-Fajardo, and Riascos-Erazo [6] manifest two profiles: professors who resist involving themselves in new methods, instruments, or ways of teaching, adducing that the methods that they have employed over such a long time have worked well and that they do not consider it necessary to make changes, and those who, with a more open mentality, are willing to be integrated into this role of teacher-innovator, in the search of improving the existing teaching techniques and proposing novel pedagogical ideals.

The perceptions of the professors differ greatly with respect to the use of ICT; notwithstanding this, due to the efforts of the Centro Universitario Ciénega, the perceptions regarding the ICT on the part of the professors has been improving, the latter manifesting themselves in the degree of utilization of these ICT. However, overtures should be continued to be made on the part of the Institution for traditional teaching in the professorial practice to evolve into an educative modality supported by the use of the ICT.

\section{Evaluation of the Learning Management System (LMS) Moodle}

Through the surveys conducted for this case study, we were able to determine that more than one half of the professors surveyed (65\%) were aware of the open source learning platform (Moodle) and that of these, $23 \%$ had already had their course published on this platform, the latter under development or active for the university community, while $12 \%$ utilized Moodle only to apply examinations. 


\section{Professors who interact with moodle}

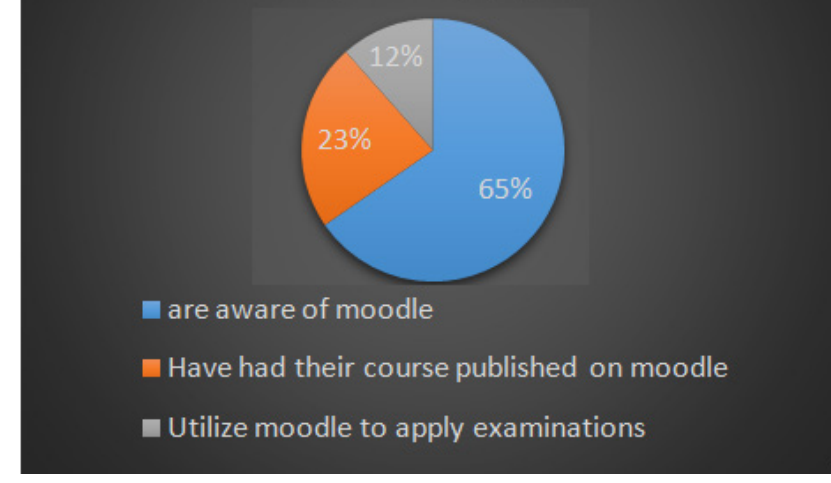

Among the perceptions that were possible to collect from the professors concerning this platform, we observed that the professors see Moodle as a space through which the element of time can be benefited in the educative process, in addition to its becoming the reference point for students to consult and get ahead in the contents of the class. On the other hand, there are professors who consider this type of platform as a very closed mechanism and of little use because, in the first place, it only allows interaction among users who have an account and access key and, in second place, Moodle appears to them to be a poorly user-friendly space where a certain measure of the skill of creativity is required to achieve satisfactory results. It is noteworthy that this latter skill is found in each of us, at different levels. In addition to this, this type of platform is not as common for students as the social networks. Thus, some professors prefer to publish their course contents on sites that are more publically accessible to all, in such a way that persons not comprising a part in the formal educative process can be included.

"The formula is short: there is no representation or communication and there is no communication without divergence" (Moscovici, 1997) [3].

The academic personnel utilizes the Moodle platform as a support tool for the application of examinations and activities.

\section{Conclusions}

The utilization of ICT in the educative task implies formation in the incorporation of ICT in teaching personnel as well as in the students, establishing educative strategies that increase motivation and diminish the generation gap existing between the two.

In the surveys taken, we were able to corroborate that the majority of the professors (58\%) became aware of the ICT tools that they employed on their own initiative, expressing interest in employing them as support tools in the classroom; another significant group (42\%) became aware of the tools through training courses, this comprising an indication level in terms of the degree to which the professors are interested in employing technologies that provide support in educative processes.
To date, many academic personnel resist the change, above all those who have been formed in the traditional model, and they consider that the better option is to continue giving their classes in the classroom. Thus, it is necessary to be able to have trained personnel who show the professors how ICT can become allies in strengthening the teaching-learning processes.

Within this context, Centro Universitario Ciénega should establish didactic strategies to present to the professors who are most resistant to the change, in order to highlight the advantages of ICT as support tools in the teaching-learning process.

Likewise, it is necessary for there to be inclusion on the part of the students, in order for the latter to become adapted to these tools, which offer to us virtual environments with truly innovative activities and resources that allow us to, little by little, understand the potentialities that this practice can exert on the formative process.

Centro Universitario Ciénega could offer formation courses that permit academic members to become students in the use of the technologies applied to education so that, with this experience, they would be able to visualize themselves in their academic task making use of the ICT as support in the teaching-learning process.

Centro Universitario Ciénega has broadened its technological infrastructure, considering ICT as technological tools for the support of teaching-learning processes, which in turn permits the construction of a structure, dynamic and collaborative, among the participants, where the teaching body is facilitated with instances of permanent formative evaluation with respect to the learning process of the student body.

Finally, communication is the basic factor in this type of process, because it comprises the main factor for sensitizing, informing, and generating the collaborative networks that allow for the appropriation of these technologies in order for there to be a truly positive repercussion on educative systems.

\section{Recommendations}

The use of ICT in the practice of teaching is not acquired overnight nor is it procured with a sole training course. It is a slow process, gradual, one involving ups and downs. Therefore, we recommend, to the teaching body that wishes to initiate an experience in the use of ICT in the classroom, planning adequately, not improvising, and being aware of the problems and technical difficulties that can arise.

Another important factor for the use of ICT in classrooms is the need of formation of the teaching personnel. The professors should be the first to use the technologies and should fully dominate them prior to incorporating them into their teaching process.

The formation of professors in the use of Information and Communication Technologies (ICT) in Higher Education is evolving in eminence.

The professorate should know how to analyze and perfect their educative practice, working in collaboration with their colleagues in common projects based on permanent formation and reflection on the educative 
practice as fundamental requisites for the development of adequate teaching processes within the new technological contexts and environments.

The should utilized collaborative work through the ICT, participating in learning communities in which everyone benefits from the knowledge of the rest of the participating members.

\section{References}

[1] Sanábria, A., \& Hernández, C. (2011). Percepción de los estudiantes y profesores sobre el uso de las TIC en los procesos de cambio e innovación en la enseñanza superior. Revista Aloma Num. 29, 2011, 273-290. Recuperado en:

http://www.revistaaloma.net/index.php/aloma/article/view/106/82.

[2] Colas, P., Jiménez R. (2008). "Evaluación del impacto de la formación (online) en TIC en el profesorado. Una perspectiva sociocultural". En: Revista de Educación num. 346, recuperado de http://www.revistaeducacion.mec.es/re346/re346_07.pdf.
[3] Moscovici, (1997). Social Representations Theory and Social Constructionism. Accessed at:

http://psyberlink.flogiston.ru/internet/bits/mosc1.htm

[4] Nolasco Salcedo, María del Carmen (2013). "Entorno virtual de aprendizaje y cursos en línea: los profesores como factor central", revista digital universitaria, Vol. 14 Núm. 11. Recuperado el 01 de noviembre en: http://www.revista.unam.mx/vol.14/num11/art49/

[5] Olcott, D. y Schmidt, K. (2002). La redefinición de las políticas y prácticas del profesorado en la era del conocimiento. En Hanna, D. La enseñanza universitaria en la era digital (pp. 265-290). Barcelona: Octaedro

[6] Quintero-Calvache, D M; Ávila-Fajardo, G P; Riascos-Erazo, S C; (2009). Las TIC en el aula: percepciones de los profesores universitarios. Educación y Educadores, 12(OJO) 133-157.

[7] Roa, M. y Stipcich, M S (2009). Adopción de las Tecnologías Infocomunicacionales (TI) en docentes: actualizando enfoques. En San Martín A, (Coord.), Convergencia Tecnológica: la producción de pedagogía high tech [monográfico en línea]. Revista Electrónica Teoría de la Educación: Educación y Cultura en la Sociedad de la Información. Vol. 10, $\mathrm{n}^{\circ} 1$. Universidad de Salamanca, España. Recuperado en:

http://www.usal.es/ teoriaeducacion/rev_numero_10_01/n10_01_ ros_stipcich.pdf ISSN: 1138-9737. 